\title{
Facing Challenges of COVID-19: The Perspective of China and Ethiopia Educational Institutions
}

\author{
Getaye Aytenew, Chang Chen* \\ Beijing University of Chemical Technology, China \\ E-mail: chenchang@mail.buct.edu.cn \\ Email: gaytenew2001@gmail.com
}

*Correspondence: Chang Chen, Beijing University of Chemical Technology, $15^{\text {th }}$ North $3^{\text {rd }}$ Ring East Road, Beijing 100029, China. Tel: 86-1-64444-2375. E-mail: chenchang@mail.buct.edu.cn

\begin{abstract}
Concerning the fast spread of COVID-19, countries all over the world have closed academic institutions to stop the pandemic. It is now apparent that students and teachers require other options that have to be more versatile, easily accessible, and support the current technologies and conditions to face the unpredictable future. From the review, literature disclosed that universities throughout the globe are establishing and implementing electronics learning platforms as a basic need in academic institutions. The manuscript aimed to assess the status of electronic learning in China and Ethiopian educational institutions to counter the challenges of the closure of educational institutions because of the outbreak of the pandemic. This review employs systematic qualitative methods to synthesize the current qualitative researches into an explanatory process to build greater sense. The paper highlights concerning e-learning in the sense of China and Ethiopia, e-learning challenges, and successful experiences. This review paper also suggests educators use e-learning and distance learning as a necessity to advance learning, particularly during this pandemic season.
\end{abstract}

Keywords: China; COVID-19; E-learning; Ethiopia

\section{INTRODUCTION}

According to UNESCO Director-General Audrey Azoulay (2020a), the world has never experienced an academic interruption on such a wide scale. Owing to the outbreak of the pandemic at the beginning of January 2020, more than 1.5 billion students disrupted from the initial teaching-learning plans, and students went back to their families and locked up together (UNESCO, 2020a). It is now evident that students and teachers require other options, the use of information communication technology (ICT). ICT has emerged as a basic need and an important tool for many countries to address the gaps in teaching and learning processes, to continue the stopped education online, and repair the normal teaching-learning order. To avoid generational catastrophe, prioritizing education recovery is fundamental (UNESCO, 2020a). This time, it has also overwhelmingly transformed conventional learning with various online strategies that are widely implemented in higher academic institutions, such as Small Private Online Courses (SPOC) and Massive Open Online Courses (MOOC) (Zhang, Wang, Yang, \& Wang, 2020). According to OECD
(2020), higher education and educational institutions showed a $300 \%$ increase in queries seeking to move to online learning.

Regarding this, the Ministries of Educational Affairs of China and Ethiopia and numerous educators and academic institutions have begun conferring and implementing the utilization of ICT to transform the entire conventional or classroom educational system to online and distance learning education. This paper, therefore, reviews the current scenario and practice of online learning in China and Ethiopia to continue the interrupted education in the country due to the outbreak of coronavirus.

\section{BACKGROUND AND DEFINITION OF E- LEARNING}

Nicholson (2007) reported that the record of electronic learning dated back to the 1960s. In the 1960s, educators and trainers have used engineering and computers in various ways to preserve, revise the system of studying, and instruct at all levels of academic institutions (Alkharang et al., 2013). Similarly, at the College of Illinois, near the beginning of the 1960s, a time-shared programming system known as 
Programmed Logic for Automatic Teaching Operations (PLATO) developed mainly focused on proficiency. It enables users to employ illustration terminals and instructions, instructive software, through electronic notes, to interact and collaborate with other customers, thus becoming the herald of today's meeting frameworks. Electronics learning is evolving rapidly, as reported by Bentley et al. (2012), supported by the maturity of ICT and a greater understanding of how to make e-courses more effective in content and delivery. They also claimed that the quick development of the worldwide provision of e-learning or online instructional courses has altered the learning atmosphere for both educators and students.

E-learning is a specific type of information system and is defined as a creative approach to the delivery of education through electronic information forms that enhances the knowledge, skills, and performance of the learner (Clark \& Mayer, 2011). As described by Koohang \& Harman (2005), electronics learning is the dissemination of all instructional activities via multiple electronic media, like the World Wide Web, local communication network, controlled private network, television, sound or formal moving pictures, etc., of all educational matters linked with teaching and delivery. E-earning also described as the utilization of ICT infrastructure towards providing teaching and instruction for learners (Sun, Tsai, Finger, Chen, \& Yeh, 2008). Elearning is by its nature flexible and adaptable, therefore, students' motivation towards e-learning must be addressed to enhance instruction policies and for better learning outcomes (Ceiesielkiewicz, 2019).

\section{The Objective of the study}

The objective of this study is to maintain continuity of the teaching and learning process for the threat of extended closures of academic institutions due to the outbreak of COVID-19. Subsequently, this study intends to examine how China and Ethiopian educational institution's teaching and learning continue during this pandemic season.

This study was guided by the following research question: What are the difficulties and successful experiences of China and Ethiopia educational institutions in response to the pandemic COVID-19 to continue the interrupted education?

\section{Significance of the study}

The findings of the study will considerably benefit various stakeholders for several reasons. It will give an insight and contribute to local literature on the subject, and which intern could use responsible authorities in their educational improvement. In addition, it will also give relevant authorities to revisit their curriculum to use ICT integrated pedagogy at higher education institutions from the experience of the two countries. Subsequently, if the recommendation of the study is well implemented, it will allow academic institutions to create an enjoyable teaching and learning environment without interruption to continue the closed education in this nationwide lockdown due to the pandemic COVID-19.
There are diverse platforms of learning environments such as Voov meeting, Tencent meeting, Google Meeting, etc., where students/learners interact and engage to learn new skills. To support learning in this pandemic, China launches two global online learning platforms, namely "XuetangX" (www.xuetangx.com) and "iCourse International" (www.icourse163.com) that are providing excellent learning resources in English and other languages around the world and consistent technical support (UNESCO, 2020b).

\section{METHODOLOGY}

In this worldwide lockdown and social distancing, an exploratory research design was found to be the most appropriate to disclose the salient complexities regarding online learning, particularly in this COVID-19 pandemic (Ali, 2020). Exploratory researches are a good way to raise questions and get a baseline of knowledge that can be used as a springboard for future study. Qualitative analysts are encouraged to identify a set of primary research studies and changing those studies into categories (Levitt, 2018). Similarly, this research employs systematic qualitative methods to synthesize the current qualitative researches into an explanatory process to build greater sense. This study was based on secondary data sources. For the collected kinds of literature, a systematic review was done in detail. The secondary sources of data used for this study are: (i) reports, (ii) journals, (iii) search engines, (iv) scholarly articles and company websites, and other academic publications.

\section{E-LEARNING TO MITIGATE LOSS OF LEARNING}

Due to the pandemic, several countries have switched to distance learning to reduce the loss of time in maintaining the shutdown of education services. Several countries simply put on their well-equipped and prepared materials to their prepared websites and make them readily available. Other countries, such as Spain, are asking teachers to plan content online and give classes online. The ICT infrastructure and awareness of the resources seem to be guiding accomplishments and learning difficulties. For instance, China effectively offers distance learning with broad connectivity, whereas others with the restricted distribution of internet access, mobile phones, or television (e.g. Vietnam, Mongolia) find it difficult to address all students equally (Tamrat \& Teferra, 2020). Moreover, many countries face difficulties when it comes to ensuring that education facilities are equally available to people with disabilities.

Most academics all over the world are encouraging elearning as a means to mitigate COVID-19 (UNESCO, 2020a). For example, top bigger world universities like Peking University, Tsinghua University, Oxford, Massachusetts University, Yale University, etc. are some of them that progressively shifted their courses online and left from the traditional modes of delivery (Picciano, 2017; Bao, 2020).

In Africa, due to the closure of higher education institutions, over 9.8 million students are experiencing disruption in their studies (Tamrat \& Teferra, 2020). The 
continent's possibility of contagion has also forced institutions to transfer their courses online. It is not, however, an easy task to go online on a continent where merely $24 \%$ of the population has access to the internet, and poor connectivity, exorbitant prices, and regular power outages are serious challenges. Thus, because of the current situation on the continent, it is not difficult to estimate the number of students in Africa that will have well-equipped access to education at the current situation on the continent. Consequently, the three key components of the information communications technology movement, i.e., internet access, power, and materials, should have to be realized on the continent of Africa to continue and promote education through e-learning. There is good motivation for expansion of e-learning education in Africa. Governments in SubSaharan Africa, in particular, have attempted to improve broadband capability and enhance campus network infrastructure through the National Education Research Networks (NRENs) (Salim, 2020).

\section{A. The Teaching Context of e-learning in China}

China is one of the world's four ancient civilizations, and its literary history dates back to the Xia Dynasty, more than 3,000 years ago. China's history is rich in the fields of literature, politics, science, and philosophy. It is the home of the oldest big civilizations in the world (http://www.chinahighlights.com). China is the most populated country in the world with a population of over 1.4 billion people.

To face the difficulties of the spread of the coronavirus pandemic, the government of China has given a notice to the people, including students from elementary to higher education, to remain at home until further announcements have been made, with approximately 276 million pupils not able to go back to class (Huang et al, 2020). More than 200 million students in China began their new online semester in February 2020 (UNESCO, 2020a). To provide versatile online learning for more than 270 million pupils, the Chinese MOE has been concerned with a proposal to continue the interrupted classes (Zhu \& Liu, 2020). With all the schools shut down, the nation embarked on what may be the leading immediate online learning exercise in human history.

The Chinese administration transformed lower schools' workbooks and instruction audios/videos for main subjects in a modern configuration that can be viewed by different electronic media over three weeks from the corona outbreak. The Ministry arranged teleconferences with school administration authorities, internet portals, and course suppliers, telecom providers, and other stakeholders to plan the realization of the initiative (UNESCO, 2020a). To this end, in conjunction with the industry office and IT, the Chinese MoE has carried out the following main tasks: (i) organize all major telecommunications service providers to boost network connection for teaching, (ii) advance the bandwidth of main education systems, (iii) leverage resources across society to deliver online courses and resources. For university students, above 24,000 online courses are made available, (iv) to promote learning follow versatile and suitable methodologies, and (v) through collaborating with the telecommunications industry and online platform service providers to improve online security.

Educators in the country have developed a quick response to the pandemic for effectively introduce online education deliverance, online class supervision and monitoring, and learning evaluation components (Zhu \& Liu, 2020). Most classes seem popular in the research. Pupils appeared to prefer e-learning, and various university lecturers have indicated that pupils appeared to be more involved than in their face-to-face delivery. The Ministry of Education has also provided essential support initiatives and established elearning technology growth targets; classroom education networks, for example, MOOCs, Chaoxing (chaoxing.com), and Zhihuishu (Zhihuishu.com) have implemented successfully (Zhao et al., 2020). They also noted that public media like Alibaba and Tencent apps highly enhanced the success of the nation's huge online education.

In addition to teachers and students, another wing that will have a great role in creating a peaceful teaching and learning environment is the parents. In China, they were against e-learning platforms, but currently, COVID-19 opens parents to fresh potential in the Chinese online transition, and their support of the online courses might cause the longlasting need for primary and secondary education online learning (Youssef, Alyousef, Hamid, \& Schaefer, 2020).

So, what lessons can educators and investors learn from China? Some of the lessons in the plurality are as follows.

(1) Redesign classes. For students at primary and secondary school, it is not practical to follow the same online class schedule. Since e-learning can't embrace students' concentration, parents should have a duty to observe their children until class ends. Therefore, the Chinese instructors re-planned the system delivery. Very long recorded videos shorten to ten minutes, which include tutorials, instructions, quizzes, etc. A few schools shortened their days from six classes to four and asked to lead the other two, such as homework or exercises. Others took a lesson from cram schools and jammed two days of the curriculum into one day, to give families a one-day break and make it easier for parents to continue working.

(2) Consider parents while teaching. When teachers are scheduling classes to teach their courses online, they will also inform the student's parents to prepare accordingly for the follow-up. This will bring a healthy teaching-learning process. In the country, instructors use automated devices and applications to work on students' results, it automatically generates students' grades and sends them directly to parents. It is very significant now than ever before to keep parents looking after their children's progress.

(3) Use contemporary teaching methods. Substantial teachers are supposed to cautiously choose and re-organize very important course materials, clear schedules, and good online platforms to avoid traditional teaching modes of delivery. Whenever lecturers and pupils lacked concentration, linkages are required like testing or interaction, etc. to stay focused more to decrease the negative effect of long-time contact. 
(4) Support low-income families financially. As described by Zhao et al. (2020), for students raised from economically poor families, who are unable to buy electronic-learning equipment or smartphones, one of the Chinese universities, Harbin University, has provided 400,000 USD to help pupils with the internet and other services. In addition to Harbin University, the University of Shanghai also provided students with iPad and 4G networked cards to support learning (UNESCO, 2020b).

(5) Provide training for teachers and pupils before class starts. An enormous e-learning platform has been recognized in China. Starting from the outbreak, universities are giving training to colleges and departments about massive online education. The training has mainly two parts: (i) online classroom by the use of different electronics meetings, and (ii) use helpful online device for instantaneous examination and survey. It helps the teachers and pupils to know how successfully utilize online education. It gives a chance to the faculty members and students to learn how successfully use the online education resource (Zhao et al., 2020).

Hallgarten and Fitzpatrick (2020) also mentioned six main important components of China's effective COVID-19 strategy to respond to the pandemic, and educators and governments need to take lessons to evolve and effectively adopt the e-learning tool. The important components are as follows: (i) differentiate responsibilities for the concerned bodies such as parents and families, (ii) when emergency policies are implemented, the decision has to be based on evidence and contact with the concerned body, (iii) quick progress of alliances and corporations, (iv) instruction and delivery via technology, (v) clear attention given for the most susceptible people, including psychology and social requirements, and (vi) flexible and committed leadership to progressively advance quality and attainment.

The Chinese major aim in the school shutdown has been to support equity. The government provides accesses like advanced network coverage, and other supplies for the most susceptible population (Zhang et al., 2020). The country MoE reacted quickly focused on establishing the delivery of e-learning and contact messages evidently for motive "Disrupted Classes, Undisrupted Learning", which provides to more than two hundred seventy million pupils (UNESCO, 2020a). Some concerned bodies highlighted the significance of accepting criticism from instructors, pupils, and parents in response to the COVID-19, and took quick measures for the success of online learning in the future.

In addition, Bao (2020) introduced six teaching techniques to enhance the focus of learning and commitment of students from previous experience to ensure a seamless transition to online learning. These are: (i) making preparation for emergency and unforeseen troubles, (ii) making the size of course contents reduced and suitable to the students for better teaching-learning, (iii) reinforcing the utilization of "voice" in lessons, (iv) running by guidance and receiving online assistance, (v) improving the active learning capacity of students outside the classroom, and (vi) successfully integrating online and offline self-learning.
Even though in China, online and distance education is not recent, Huang et al. (2020) revealed that in these uncertain and severe conditions, the key obstacles currently posed concerning the performance of this sort of method are: (i) lack of preparation, (ii) isolation of teachers/students, and (iii) the need for effective pedagogical approaches. To keep students inspired and engaged during this time of online learning, open teaching methods, cooperation, and open evaluation should be put into effect.

\section{B. The Teaching Context of e-learning in Ethiopia}

In the previous sections, we have seen the teaching context and experiences of China to counter the closure of academic institutions due to the outbreak of COVID-19. In this section, we have presented the Ethiopian academic institution's response to the pandemic outbreak.

Ethiopia is a country situated in East Africa; it is also among the world's oldest countries. It is the $2^{\text {nd }}$ most populous country after Nigeria in Sub-Saharan Africa. Ethiopia is a big, land-locked, and diversified nation with more than 90 ethnic and linguistic groups and above 110 million people.

Over the past decades, Ethiopia has recognized the value of ICT and developed a carefully structured roadmap to tackle the obstacles and opportunities of exploiting its power to facilitate the quality and distribution of general education for the growth of the country (Anberbir, 2015). While ICTs are recognized by the country's education policy as an enabler to increase access to education, the system is still at its infancy stage and has not brought anticipated reforms or outcomes. The outbreak of this pandemic, however, prompted the government to use e-learning as an alternative way to continue the disrupted education.

In lower schools, the government of Ethiopia started satellite television (through the Ministry of education TV and other public TVs) and radio transmission programs using different languages of the country. Nevertheless, it is challenging due to the limited ICT infrastructure, as well as knowledge and experience in scriptwriting and production for broadcasting, the nature of multilingual regions such as South Nations and Nationalities with 32 mother tongue languages, and monitoring attendances in class (The knowledge synthesis team, 2020).

The Ethiopian ministry of higher education developed a roadmap intended for the country's higher education institutions to address the challenges and opportunities of influencing the power of ICTs to improve the quality and delivery of general education. Ethiopian higher education has therefore mobilized ICT workers, invested in it, and made efforts to use it for education, particularly in the fields of course management systems, library automation, automated libraries, and information systems for student management. The new ICT employment system with a higher pay scale has been introduced by most universities, and this allows universities to maintain IT practitioners.

The establishment of higher education discussion by MOE to exchange information and resources among universities is another important move that is helping 
universities to use ICT for education. The MOE planned and implementing different strategies following its previous elearning initiatives to continue the stopped education in the country. Some of the actions implemented to face the challenges were:

(1) Online digital library link. The ministry developed the National Digital Library of Ethiopia (NADLE) for educators and students to provide easy access to e-course materials, ebooks, and online courses for TVET, undergraduate degree, and postgraduate studies. It also comprises databases of academic articles and databases of publishers / high indexed journals, data sets and data archives, papers and videos, journals, etc. ( http://ndl.ethernet.edu.et/).

(2) The use of Telegram, What's up group, and group emails. By the order of MoSHE, all the departments/faculty/colleges in the country created telegram, email, and what's up groups for their students. Teachers, department heads, the institute deans, and the university vice presidents added or joined the group so that they can easily follow and manage the teaching-learning process in the group. Teachers deliver their course materials and even continuous assessments like projects, assignments, and quizzes to their students online or offline.

(3) Zoom meeting App. The other action taken by the ministry is the use of Google meeting applications. Many instructors, especially for postgraduate students, currently use this application. The uses of website and telegram groups are not that effective to assess and address students. So, teaching using Google meeting apps is currently established and tried to address for postgraduate and undergraduate students and get greater acceptance from the student's side in their interview in different media of the country.

The other opportunity for students and teachers is that the MoSHE is working with Ethiopia Telecom to realize the economic potential of students while providing education online. Accordingly, they decided that students and teachers of higher education should use the digital library free of charge when students and teachers visit the site. The library contains over 80,000 reference books, five-year university students' modules, image-assisted tutorials, and course materials for all subjects of undergraduate and postgraduate programs (FBC, 2020b).

\section{Challenges of E-Learning Provisions in Ethiopia}

As described by Islam et al. (2015), educational institutions face many problems with the utilization and achievement of online learning in an educational setting, such as learning styles, teaching methodology, culture, technological guidance, etc. According to Kisanga and Ireson (2015), the introduction of electronic learning in Tanzania's academic institution had faced five difficulties or barriers: weak facilities, financial restrictions, insufficient funding, shortage of electronics learning experts, and resistance of teachers to challenge. Khan et al. (2012) also argued that e-learning has faced similar difficulties related to ICT resources, inadequate funding, uncertain strategies, political variables, cultural variables, attitudes of students, ICT expertise, and lack of time. Likewise, four main challenges in e-learning have also been summarized by Carliner and Shank (2008): systemic hurdles, technological, pedagogical, and financial problems.

Similarly, Ethiopia is also experiencing different challenges to continue the disrupted education through electronic learning tools. Some of the most possible barriers that are hindering the success of the utilization of technology in the country are as follows.

(1) Access challenges. In Ethiopia, nearly $83 \%$ of the population lives on agriculture (World Bank Group, 2016). This shows most of the populations in the country live in rural areas. Students raised in this area cannot even find enough electricity and network access to continue their education online. In addition, many students in the area are from poor families, and they do not have smartphones. In the absence of electricity, network access, and electronic materials, it is very difficult to address these students online, and it will broaden the knowledge gap between students.

(2) Challenges regarding teaching methodology. Teaching methodology deals with facilitating the effective way to accomplish the instruction medium (Islam et al., 2015). If pedagogy is not considered, then the preferred learning result will not be accomplished. The successful method of teaching involves the instructor helping the students learn, then properly plan and execute class content, then tutor students, to pass on competencies and understanding. Teaching methods ought to be the foundation of every technology for e-learning. It will be hampered without primary pedagogical learning. In the country, there is no pedagogical training given to teachers, so teachers do not have good knowledge on encouraging their students using e-learning.

(3) Challenges related to practical training. Technical training is to indicate the instruction circumstance that will allow educators and online teaching platforms or other technical issues and support to implement it successfully. However, in Ethiopia, due to the limited resources and limited trainers available, it is very hard to give technical training for all instructors to use and access e-learning successfully.

(4) Technology, instructor, and student characteristics. Volery and Lord (2000) exposed the three criteria required for successful performance in e-learning such as infrastructure, characteristics of the teacher, and characteristics of the student. Technology has to advance, but in terms of providing a good learning environment, the characteristics of the instructor and understanding of technology are most important. Teachers that are inspired and contain an optimistic approach towards online learning technologies can make a constructive learning outcome possible. It is important that the teacher has strong technology management and can solve simple problemsolving activities.

(5) Learning approach and cultural challenges. Everyone, along with their cultural influences, has their learning style; in academics, students who are taught using 
their way of teaching-learning approach, their culture and background will achieve a very good result (Sywelem et al., 2012). Students in Ethiopia have experienced only traditional modes of delivery, and the use of e-learning technologies is not usual. Therefore, it will take more time to establish and make students friendly with the new online education policy, even if the above challenges are resolved.

It also stated that electronic learning overcomes several challenges that are intrinsic to traditional delivery, especially its lack of resource versatility (Buzzetto-More, 2008). There are quite a few issues to be addressed in the use of e-learning: learning framework, availability, qualified IT human resources, material supplier, etc. Fulfilling this is a significant move to the successful accomplishment of elearning tools. To do so requires a considerable venture and dedication on the part of educational institutions (Kebede, 2001)

Yenework (2017) in her assessment of e-learning readiness in Ethiopia revealed that teachers regarding technology access and attitudes towards successful online teaching, students regarding attitudes towards a successful online learner, administrators regarding administrative support, and ICT experts regarding their responsibility, were ready to use e-learning but needs improvements.

Anberbir (2015) in his survey of the use of e-learning in fourteen Ethiopian higher education institutions, found that the university's ICT staffs are trying to implement ICT for academic development and working to join e-learning into teaching-learning processes. Except for a few universities, due to the lack of awareness by teachers and administrative staff, the implementation of electronic learning in education and ICT integration in the teaching-learning process is still in the initial stages. In addition, he also reported that $55 \%$ of university respondents used electronic learning for the mixed modes to support the teaching-learning process.

With its limitation, Ethiopian universities having previous blended e-learning experiences are completing the interrupted education online, especially for postgraduate program students. Some universities, for example, the University of Gondar and Addis Ababa University graduated their MSc and Ph.D. students online via the abovementioned systems. Other universities are trying to complete their postgraduate students online by following these two universities' experiences. However, the established elearning platform in the country is not enough to finish the stopped education successfully.

Due to the difficulty of online classes and distance learning delivery in the country, the MOE decided to reopen classes. In the country, except for grade 8 and grade 12 students (students who will take national and regional examinations), the ministry of education decided for other classes to pass to the next level. The decision does not consider higher education institution students; it is only for students from grades 1-12.

Since October 5, 2020, all educational institutions in Ethiopia started face-to-face delivery and continue the teaching process by adapting the global guidance for reopening schools (FBC, 2020a). However, according to the country's Ministry of Health daily report, the spread of the virus is still increasing at an alarming rate.

When students return to school, institutions recommended using blended modes of learning to cover the course contents. Due to the pandemic, teachers should have a very limited time contact in the classroom. According to El-Mowafy (2013), teachers should use tools in surveying education, like the simulation-based e-learning (SIMBEL) tool. In Ethiopia, based on the difficulty of the courses, some courses delivered online, some blended and other courses delivered in face to face by the decision of the department. In the country, two semesters finished effectively with this delivery system. SIMBEL tool is an effective tool applied to cover the courses for both fully online and the blended modes of delivery. It has many advantages such as (i) it provides a great potential to enhance practical skills in a virtual environment in cases of limited time and resources, (ii) it can provide a good-quality option to classroom training, and (iii) it provides the utilization of e-assessment as a marking, control, and feedback tool, and peer evaluation.

Therefore, educators and other concerning bodies should have to share many experiences from both countries and reevaluate the strategic plan regarding e-learning methods of the country to ensure successful e-learning for lower grades, undergraduate and postgraduate studies by considering students' health issues.

\section{OPPORTUNITIES}

Tegegne (2014) mentioned that e-learning has many benefits such as e-learning helping students to experience working independently, cooperative learning, and supporting pupils to become advanced in technology, using their extra time effectively, etc. E-learning technology is generally described as the most successful way to improve learners' socialization and self-realization skills for the rest of their future carrier (Dalayeva, 2013). Therefore, after this pandemic has gone out, and on the positive side, if this threat and the approach to overcome it through e-learning is successful, there comes catalytic long-lasting reform in China and Ethiopian education institutions. This pandemic will allow many countries all over the world to blend online learning as a means for the expansion of education. It will address quality education for students without leaving their homes through e-learning technology. E-learning has various benefits such as it accommodates every one's needs, can access the content for unlimited time, offers access to updated contents, can deliver lessons quickly, enhance capability to learn and self-improvement, and also it is environmentally friendly (www.Ahduweb.com). Moreover, the COVID-19 pandemic gives a great lesson and experience to the world for the unpredicted future.

This pandemic also gives lessons to the world academic institutions. Some of the lessons and opportunities influenced by COVID-19 are: (i) integrated models of education delivery will be broadly used (online and face to face delivery will be integrated), (ii) cooperation amongst academicians can be developed and will help advance learning, (iii) quality education resources will be obtained 
and broadly used, (iv) the circumstances will help academician to interconnect without border and go jointly, and (v) if the same or the worst scenario comes in the future, the academicians will continue classes with e-learning or distance learning without disruption.

\section{CONCLUSION AND RECOMMENDATIONS}

To sum up, the outbreak of COVID-19 tested the world government a lot. The pandemic has brought about an immense interruption to every aspect of human life. To reduce the spread of the pandemic, educational institutions are closed almost all over the world. To continue the interrupted education when classes are disrupted, different countries shifted from traditional schools to online learning. In this review, the e-learning experiences and status of academic institutions in China and Ethiopia were assessed. These two countries are historically, economically, geographically, politically, demographically, and socially distinct nations. Both nations run education systems within their diverse dimensions of ethnicity, language, socioeconomic background, and whatever other variations counted.

To face the challenges of the closure of educational institutions with robust technology, China has given a quicker response to the pandemic by launching an initiative "disrupted classes, uninterrupted learning" and successfully implemented online education. On the other hand, Ethiopia is also implementing e-learning platforms to counter the existing problem, and universities in the country graduated their students online successfully. To this success, the Ethiopian MOE developed an online digital library link, created a telegram group channel, What's up group, and through group emails and by using Google meeting application etc. for free of charges when students and teachers visit the site.

In both countries, the use of e-learning systems is correlated with various challenges such as accessibility issues, pedagogical e-learning difficulties, technical challenges, teacher and student characteristics, and ways of learning and cultural challenges. These difficulties are important for comprehension for every academic that require strong electronic learning results (Islam et al., 2015). Improving those challenges will allow any academic institution to advance and meet the education goals.

Generally, from the e-learning experience of China and Ethiopia, educators around the globe will get lessons to improve the online teaching and learning process; educational institutions should have to develop and implement e-learning platforms to influence the current situation as well as the unpredictable future.

\section{REFERENCES}

Ali, W. (2020). Online and remote learning in higher education institutes: A necessity in light of COVID19 pandemic. Higher education studies, 10(3), 1625.
Alkharang, M. M., \& Guinea, G. (2013). E-learning in higher educational institutions in Kuwait: Experiences and challenges. International Journal of Advanced Computer Science and Applications, 4(4), 1-6.

Anberbir, T. (2015). Survey of the use of e-learning in higher education in Ethiopia. E-learning conference 2015.

Bao, W. (2020). COVID-19 and online teaching in higher education: A case study of Peking University. Human Behavior and Emerging Technologies, 2(2), 113-115.

Bentley, Y., Selassie, H., \& Shegunshi, A. (2012). Design and evaluation of student-focused e-learning. Electronic Journal of e-Learning, 10(1), 1-12.

Buzzetto-More, N. (2008). Student perception of various elearning components. Interdisciplinary Journal of e-learning and Learning Objectives, 4(1), 113-135.

Carliner, S., \& Shank, P. (2008). The e-learning hand book: Past promises to present challenges. London: John Wiley \& Sons.

Ceiesielkiewicz, M. (2019). The use of e-portfolios in higher education: From the studies perspective. Issues in International Education, 29(3), 649-667.

Clark, R. C., \& Mayer, R. E. (2008). E-learning and the science of instruction: Proven guidelines for consumers and designers of multimedia learning. London: John Wiley \& Sons.

Dalayeva, T. (2013). The e-learning trends of higher education in Kazakhstan. Procedia-Social and Behavioral Sciences, 3rd World Conference on Learning, Teaching and Educational Leadership, 93, 1791-1794.

El-Mowafy, A., Kuhn, M., \& Snow, T. (2013). Blended learning in higher education: Current and future challenges in surveying education. Issues in Educational Research, 23(2), 132-150.

FBC. (2020a). Ethiopia set to reopen schools next academic year. Welcome to Fana Broadcasting Corporate S.C. Retrieved June 21, 2021, from https://www.fanabc.com/english/ethiopia-set-toreopen-schools-next-academic-year/.

FBC. (2020b, June 1). MoSHE opens digital library for teachers, students. Welcome to Fana Broadcasting Corporate S.C. Retrieved June 22, 2021, from https://www.fanabc.com/english/moshe-opensdigital-library-for-teachers-students/

Hallgarten, J., \& Fitzpatrick, R. (2020). What can be learnt from China's recent experiences with COVID-19 and school closures that can inform other countries' education technology-enabled responses? EdTech $H u b$. Retrieved June 21, 2021, from https://edtechhub.org/what-can-be-learnt-fromchinas-recent-experiences-with-covid-19-andschool-closures-that-can-inform-other-countrieseducation-technology-enabled-responses/

Huang, R., Liu, D., Tlili, A., Yang, J., \& Wang, H. (2020). Handbook on facilitating flexible learning during 
educational disruption: The Chinese experience in maintaining undisrupted learning in COVID-19 Outbreak. Beijing: Smart Learning Institute of Beijing Normal University.

Islam, N., Beer, M., \& Slack, F. (2015). E-learning challenges faced by academics in higher education. Journal of Education and Training Studies, 3(5), 102-112.

Kebede, A. (2001). Distance education initiative for Ethiopia. International Conference on African Development Archives, 16.

Khan, M. S. H, Hasan, M., \& Clement, C. K. (2012). Barriers to the introduction of ICT in education in developing countries: The example of Bangladesh. International Journal of Instruction, 5(2), 61-80.

Kisanga, D., \& Ireson, G. (2015). Barriers and strategies on adoption of e-learning in Tanzanian higher learning institutions: Lessons for adopter. International Journal of Education and Development using ICT , 11(2), 126-137.

Koohang, A., \& Harman, K. (2005). Open source: A metaphor for e-learning. Informing Science: The International Journal of an Emerging Transdiscipline, 8, 75-86.

Levitt, H. M. (2018). How to conduct a qualitative metaanalysis: Tailoring methods to enhance methodological integrity. Psychotherapy Research, 28(3), 367-378.

Nicholson, P. (2007). A history of e-learning. In B. Fernández-Manjón, J. M. Sánchez-Pérez, J. A. Gómez-Pulido, M. A. Vega-Rodríguez, \& J. BravoRodríguez (Eds.), Computers and education: $e$ learning, from theory to practice (pp. 1-11). Dordrecht: Springer Netherlands.

OECD. (2020). Lessons for education from COVID-19: A policy maker's handbook for more resilient system. Paris: OECD Publishing.

Picciano, A. G. (2017). Theories and frameworks for online education: Seeking an integrated model. Online Learning, 21(3), 166-190.

Salim, J. (2020). COVID's lessons for global higher education: coping with the present while building a more equitable future. Indianapolis: Lumina Foundation.

Sun, P. C., Tsai, R. J., Finger, G., Chen, Y. Y., \& Yeh, D. (2008). What drives a successful e-Learning? An empirical investigation of the critical factors influencing learner satisfaction. Computers \& Education, 50(4), 1183-1202.

Sywelem, M., Al-Harbi, Q., Fathema, N., \& Witte, J. E. (2012). Learning style preferences of student teachers: A cross-cultural perspective. Institute for Learning Styles Journal, 1, 10-24.

Tamrat, W., \& Teferra, D. (2020, April 9). COVID-19 poses a serious threat to higher education. University World News. Retrieved June 21, 2021, from https://www.universityworldnews.com/post.php?stor $\mathrm{y}=20200409103755715$
Tegegne, K. M. (2014). Perception of university students before and after the e-learning implementation in one of the mathematics courses: The case of mathematics students in Jimma University. Ethiopian Journal of Education and Sciences, 9(2), 61-82.

The knowledge synthesis team (2020). Lessons from global evidence on school re-opening in the era of COVID-19. Addis Ababa: CDT-AFRICA Addis Ababa University.

UNESCO. (2020a, February 19). How is China ensuring learning when classes are disrupted by coronavirus? UNESCO. Retrieved June 21, 2021, from https://en.unesco.org/news/how-china-ensuringlearning-when-classes-are-disrupted-coronavirus

UNESCO. (2020b). Online and open education in Shanghai: Emergency response and innovative practice during COVID-19 pandemic. Shanghai: UNESCO Institute for Information Technologies in Education.

Volery, T., \& Lord, D. (2000). Critical success factors in online education. International Journal of Educational Management, 14(5), 216-223.

World Bank Group. (2016). Ethiopia priorities for ending extreme poverty and promoting shared prosperity (No. 100592-ET)

Yenework, B. (2017). Assessment of e-learning readiness of Assosa University (Thesis). Addis Ababa: Addis Ababa University.

Youssef, J., Alyousef, A., Hamid, D., \& Schaefer, J. (2020). Education continuity during COVID-19. OLIVER WYMAN.

Zhang, W., Wang, Y., Yang, L., \& Wang, C. (2020) Suspending classes without stopping learning: China's education emergency management policy in the COVID-19 outbreak. Journal of Risk and Financial Management, 13(3), 55.

Zhao, J., Xiao, H., Y., L., Wen, P., \& Xu, Y. (2020). Experience of massive distance online education for medical colleges and universities in china to counter the COVID-19 Pandemic. Research Square.

Zhu, X., \& Liu, J. (2020). Education in and after COVID-19: Immediate responses and long-term visions. Postdigital Science and Education, 1-5. 